\title{
BULLYING: O COMPORTAMENTO VIOLENTO NO ÂMBITO ESCOLAR, SUA INTERFERÊNCIA NO PROCESSO DE APRENDIZAGEM E O PAPEL DA FAMÍLIA NA DISSOLUÇÃO DESSE CONFLITO
}

\author{
Juliana Rui Fernandes dos Reis Gonçalves*
}

SUMÁRIO: Introdução; 2 O Bullying: Violência no Âmbito Escolar e suas Consequências; 3 A Interferência do Bullying na Aprendizagem e o Papel da Escola para sua Superação; 4 O Papel da Família para Resolução desse Conflito; 5 Considerações Finais; Referências.

RESUMO: O Bullying é um termo de origem inglesa que trata do conjunto de atitudes violentas de caráter intencional e repetitivo, realizado por um ou mais agressores, contra suas vítimas, sendo uma prática encontrada no meio escolar, a qual é realizada tanto por garotos quanto por garotas, com o fim de agredir intencionalmente uma pessoa ou um grupo de pessoas, considerado pelos agressores como pessoas fracas e que "destoam" do meio onde estão inseridas. A preocupação com o bullying tem sido crescente na sociedade contemporânea, tendo em vista o número de casos que têm gerado verdadeiras barbáries no meio escolar. As vítimas de bullying, em função de todos os aspectos da violência sofrida, poderão vir a desenvolver diferentes doenças psíquicas e/ou físicas, as quais tendem a comprometer o seu desempenho escolar por diminuição da concentração, desinteresse gradual pelos estudos, dificuldade de aprendizagem, o que pode gerar exclusão, faltas e evasão escolar, pelo fato de que o aluno vítima tem a escola como um local de sofrimento, de segregação. A Escola, além de conhecer como se dá o processo de aprendizagem, deve perceber aquilo que ocorre com os seus alunos, reconhecendo os fatores que interferem no aprendizado destes, sendo o bullying fato determinante no que diz respeito à diminuição do rendimento escolar. Sendo assim, essa violência se mostra como um problema para a convivência dos alunos na escola que pode até mesmo transpassar os seus muros, devendo, por isso mesmo, ser percebida e combatida de forma sistemática. Ademais, não basta que essa prática seja conhecida e combatida na escola para que se consiga sua diminuição, tendo os pais um papel importante na solução desse problema. Dessa forma, buscar-se-á analisar o fenômeno Bullying no ambiente escolar e sua interferência nos processos de aprendizagem e o papel da família na dissolução desse conflito.

PALAVRAS-CHAVE: Bullying; Família; Interferência no Rendimento Escolar; Violência.

Mestre em Direito pela Universidade Estadual de Maringá (UEM); Advogada; Docente dos Cursos de Graduação em Direito da Faculdade Cidade Verde (FCV) e de Pós-Graduação da Faculdade Metropolitana de Maringá (FAMMA), Brasil: E-mail: profjulianarui@gmail.com 


\title{
BULLYING: A VIOLENCE BEHAVIOR IN THE SCHOOL, ITS INTERFERENCE IN THE LEARNING PROCESS AND THE ROLE OF THE FAMILY IN THE SOLUTION OF CONFLICTS
}

\begin{abstract}
Bullying consists of a set of intentional and repeated violent attitudes by one or more aggressors against their victims. It is normally practiced in schools by people of both genders to intentionally harm a person or a group of persons who in the aggressors' opinion are weak people and do not "fit" in the milieu in which they are inserted. Bullying has been a concern in contemporary society due to the high number of cases producing horrible scenes in school. The victims of bullying may develop different psychic or physical diseases due to violence, which may impair school performance through low concentration, lack of interest in studies, learning difficulties, causing exclusion, school truancy or quittance due to the student's fixation that the school is a place of torture and segregation. School administration should acknowledge what happens to the students and pinpoints the factors that interfere in learning. In fact, bullying is a determinant with regard to decrease in school performance. Violence is a problem within the conviviality of students in the school and it may go beyond its boundaries. Consequently, it must be perceived and attacked systematically. Further, parents have an important role in its solution. The paper deals with bullying within the school and its interference in the learning process, coupled to the family's role for the solution of the problem.
\end{abstract}

KEY WORDS: Bullying; Violence; Interference in School Performance; Family.

\section{BULLYING: EL COMPORTAMIENTO VIOLENTO EN EL ÁMBITO ESCOLAR, SU INTERFERENCIA EN EL PROCESO DE APRENDIZAJE Y EL PAPEL DE LA FAMILIA EN LA DISSOLUCIÓN DE ESE CONFLICTO}

RESUMEN: El Bullying - que en español también puede ser conocido como acoso - es una palabra de origen inglesa que refiere un conjunto de actitudes violentas de carácter intencional y repetitivo, realizado por uno o más agresores, contra sus víctimas, siendo una práctica encontrada en el entorno escolar, la cual es realizada tanto por chicos como por chicas, con la finalidad de agredir intencionalmente una persona o un grupo de personas, considerado por los agresores, como personas débiles y que "desentonan" del medio donde están inseridas. La preocupación con el bulling es creciente en la sociedad contemporánea, una vez que se observa la cantidad de casos que generan verdaderas barbaries en el entorno escolar. Las víctimas del bulling, debido a la violencia sufrida, podrán desarrollar distintas enfermedades psíquicas y/o físicas, las cuales pueden comprometer el desarrollo escolar a causa de 
la disminución de concentración, desinterés gradual por los estudios, dificultad de aprendizaje, lo que puede llevar a la exclusión, faltas y evasión escolar, una vez que el alumno victima toma la escuela como un local de sufrimiento, de segregación. La escuela, además de conocer como ocurre el proceso de aprendizaje, debe percibir aquello que ocurre con sus alumnos, reconociendo los factores que interfieren el aprendizaje de estos, siendo el bulling un hecho determinante en lo que se refiere a la disminución del rendimiento escolar. Siendo así, esa violencia, se muestra como un problema para la convivencia de los alumnos en la escuela que puede, incluso, traspasar sus fronteras, debiendo, por ello, ser observada y combatida de forma sistemática. Además, no basta que esa práctica sea conocida y combatida en la escuela para que se logre su disminución, ya que los padres poseen un papel importante en la solución de ese problema. De esta manera, se busca analizar el fenómeno Bulling en el entorno escolar, y su interferencia en los procesos de aprendizaje y el papel de la familia en la disolución del conflicto.

PALABRAS-CLAVE: Bulling; Violencia; Interferencia en el Aprendizaje; Familia.

\section{INTRODUÇÃO}

Atualmente tem-se buscado entender um fenômeno que existe há muito tempo no cotidiano das escolas de todo o mundo, mas que, enquanto estudo científico acerca dos seus aspectos bio-psíquicos-sociais buscar-se-á contribuir com relação à análise de suas consequências no âmbito escolar.

O bullying, como é conhecido mundialmente, é uma prática realizada no meio escolar, tanto por garotos quanto por garotas, com o fim de agredir intencionalmente uma pessoa ou um grupo de pessoas, considerados pelos agressores como pessoas fracas e que "destoam" do meio onde estão inseridas.

O termo, de origem inglesa, vem designar o conjunto de atitudes violentas, cruéis, de violência física e/ou psíquica, de caráter intencional e repetitivo, realizado por conjunto de agressores contra uma ou mais vítimas, sem condições de defesa ${ }^{1}$, causando-lhes angústia, sofrimento, os quais podem se transformar em diferentes doenças que acompanharão as vítimas por toda sua vida, se não forem devidamente diagnosticados e tratados.

Seria uma espécie de assédio moral, com atos e consequências que podem sair do âmbito psíquico, e se transformar em doenças físicas, afetando o rendimento

\footnotetext{
${ }^{1}$ SILVA, Ana Beatriz Barbosa. Bullying: mentes perigosas nas escolas. Rio de Janeiro: Objetiva, 2010, p. 21.
} 
escolar do indivíduo reduzido à vítima do bullying, tendo em vista que a prática desse tipo de violência segrega suas vítimas do convívio social sadio, o que, comprovadamente, já se demonstrou como fator fundamental para se alcançar um melhor nível de aprendizado ${ }^{2}$.

Ademais, dependendo do grau da violência sofrida, do momento da sua constatação e da forma como for tratado o sujeito vitimado, esse processo poderá afetar não somente a vida escolar da vítima, mas também gerar consequências para além desta, em sua vida familiar e, no futuro, na vida profissional, sendo necessário, portanto, que tanto a Escola como a família se envolvam na discussão do tema para que se consiga achar soluções para esse problema.

\section{O BULLYING: VIOLÊNCIA NO ÂMBITO ESCOLAR E SUAS CONSEQUÊNCIAS}

A preocupação com o bullying tem sido crescente na sociedade contemporânea, bem como também o número de casos que tem gerado verdadeiras barbáries no meio escolar, cite-se o caso do colégio Columbine High School, em Denver, Colorado, EUA, no ano de $1999^{3}$, onde dois estudantes assassinaram outros doze, um professor e feriram mais vinte pessoas, e depois se suicidaram, o que foi posteriormente relatado no documentário "Tiros em Columbine" (2002), dirigido por Michael Moore; o caso ocorrido no campus da Virgina-Tech, no Estado da Virgínia, EUA, no ano de 2007, quando o sul-coreano Cho Seung-hui, de 23 anos, matou trinta e duas pessoas entre alunos e professores daquela universidade, e feriu outras vinte, antes de ser morto; na Alemanha, em 2009, em uma escola de Winnenden, um adolescente de 15 anos matou 15 pessoas, sendo morto posteriormente pela polícia, ou cometido suicídio ${ }^{4}$; no Brasil, destacam-se os casos ocorridos em Táuva, Estado de São Paulo5, e em Realengo, zona Oeste da cidade do Rio de Janeiro, ocorrendo o primeiro em janeiro de 2003, quando Edmar Aparecido Freitas, de 18 anos, feriu oito pessoas no colégio onde estudava e depois se matou e, o segundo, em abril de

2 LOPES NETO, Aramis A. Bullying: comportamento agressivo entre estudantes. Jornal de Pediatria, v. 81, n. 5, S164-172, 2005. Disponível em: < http://www.observatoriodainfancia.com.br/IMG/pdf/doc-158.pdf >; e também em: <www.scielo.br/pdf/jped/v81n5s0/v81n5Sa06.pdf> Acesso em: 10 set. 2011, p. 167.

3 SILVA, Elenice da. Corredores de justiça: combatendo a prática do Bullying nas escolas, educando uma sociedade para a paz. São Paulo: Ed. do Autor, 2009, p. 40.

${ }^{4}$ LIMA, Raimundo de. Massacre nas Escolas. Revista Espaço Acadêmico, n. 96, maio de 2009. Disponível em: $<$ http://www.espacoacademico.com.br/096/96lima.htm> Acesso em: 05 nov. 2011.

5 SILVA, Elenice da, op. cit., p. 42. 
2011, quando pelo menos onze estudantes foram mortos e dezoito foram feridos, na Escola Municipal Tasso da Silveira, tendo sido o atirador morto para que não ferisse mais pessoas.

Todos os casos acima relatados foram situações onde se constatou que os atiradores foram vítimas de bullying, tendo reagido às agressões sofridas de forma extrema.

Especialistas no assunto têm relatado que a violência gerada pelo bullying acaba por roubar a infância das vítimas dessa agressão $0^{6}$, levando-se em conta que as crianças e adolescentes submetidos a esse ataque, segundo a literatura, poderão vir a apresentar um ou mais sintomas psicossomáticos como: distúrbios alimentares, cefaleia (dor de cabeça), cansaço crônico, insônia, dificuldades de concentração, náuseas, diarreia, boca seca, palpitações, alergias, crise de asma, sudorese, tremores, sensação de "nó" na garganta, tonturas, desmaios, calafrios, tensão muscular, formigamentos, ataques de pânico (que gera medo e ansiedade em demasia, podendo resultar em taquicardia, calafrios, boca seca, dilatação da pupila, suores, falta de ar, etc.), fobia escolar, transtorno de ansiedade social (TAS ou fobia social), transtorno de ansiedade generalizada (TAG) com medo e insegurança persistente, transtorno obsessivo-compulsivo (TOC ou manias/obsessões), transtorno do estresse pós-traumático (TEPT), depressão, anorexia, bulimia e/ou esquizofrenia ${ }^{7}$, doenças estas que poderão interferir direta ou indiretamente no rendimento escolar da vítima de bullying, podendo levar estas até mesmo ao suicídio e/ou ao homicídio por vingança ${ }^{8}$, como nos casos anteriormente citados?.

Cabe acrescentar ainda que, normalmente, as vítimas de agressões constantes são pessoas que têm baixa autoestima por não se enquadrarem nos padrões apresentados pelo grupo, pouca habilidade de socialização, sendo, em geral, tímidas e frágeis, portanto, mais vulneráveis em relação aos bullies (agressores), não conseguindo reagir à violência a elas dirigida, colocando-se em uma situação de permanente submissão àqueles que lhes agridem.

Contudo, também há casos em que a vítima de bullying pode agir de forma provocadora, insuflando em seus colegas reações agressivas contra elas

\footnotetext{
${ }^{6}$ JORDÃO, Cláudia. Entrevista Allan Beane: as escolas fecham os olhos ao bullying. Revista Isto É. São Paulo, 21 abril 2010. p. 9-11.

SILVA, Ana Beatriz Barbosa Silva, op. cit., p. 22-31.

8 Idem.

9 FANTE, Cleo. Fenômeno Bullying: como prevenir a violência nas escolas e educar para a paz. 6. ed. Campinas: Verus, 2011, p. 45.
} 
mesmas $^{10}$, como o caso de crianças que sofrem de transtorno do déficit de atenção com hiperatividade (TDAH ou hiperatividade), tendo em vista que estas, por serem muito ativas, criam em volta de si (sem qualquer intenção de fazê-lo) um ambiente tenso, o que acaba por chamar a atenção de todos para si, inclusive dos verdadeiros agressores, que se escondem nesse ambiente e fazem ataques sem serem percebidos, já que a vítima chama mais atenção que estes.

O aluno vítima de bullying, portanto, em função de todos os aspectos já destacados, não terá na escola um local onde poderá se desenvolver plenamente, de forma a buscar aquilo que Piaget explicita como "lei do interesse" (ou seja, o fato de que o bom educador deverá suscitar em seus alunos o trabalho espontâneo, baseado na necessidade e no interesse pessoal, sem manipulação, mas sim com interesse real no que está sendo estudado ${ }^{11}$, visto que este estudante terá na escola um local de tormentos e de angústia, o que leva ao desinteresse e ao medo de frequentar o ambiente escolar, com possível déficit de concentração e aprendizagem, queda no rendimento escolar, repetência e, até mesmo, a evasão ${ }^{12}$, o que demonstra uma falha da escola no cumprimento do papel social de formação do aluno.

Ademais, no que concerne à saúde física e emocional da vítima, esta poderá ter vários problemas físicos como os anteriormente destacados, além de crises de ansiedade, estresse, transtornos psicológicos, podendo até mesmo chegar ao suicídio e/ou homicídio. Cabe ressaltar ainda que:

Em um levantamento realizado pela ABRAPIA (Associação Brasileira Multiprofissional de Proteção à Infância e a Adolescência), em 2002, no Rio de Janeiro, entre 5.875 estudantes de quinta a oitava séries, mais de $40 \%$ desses alunos tiveram experiência em atos de bullying, somente naquele ano.

Os dados sobre a violência em uma pesquisa realizada em 2009, pelo Instituto Brasileiro de Geografia e Estatística (IBGE) revelaram que quase um terço dos alunos $(30,8 \%)$ respondeu ter sofrido bullying alguma vez. A ocorrência foi verificada em maior proporção entre alunos de escolas privadas (35,9\%) do que entre os de escolas públicas (29,5\%). A pesquisa também apontou as cidades de Brasília e Belo Horizonte como as capitais brasileiras com maiores índices de bullying: $35,6 \% \mathrm{e}$ $35,3 \%{ }^{13}$

\footnotetext{
10 SILVA, Ana Beatriz Barbosa Silva. op. cit. p. 40.

11 PIAGET, Jean. O juízo moral na criança. 2. ed. São Paulo: Summus, 1994, p. 35.

12 COMPORTAMENTO: bullying. Revista Psicanálise, n. 1, p. 38-45, 2010.

13 ABRAPIA. Associação Brasileira Multiprofissional de Proteção à Criança. Pesquisa realizada pela ABRAPIA em 2002/2003 no município do Rio de Janeiro. Disponível em: < http://www.observatoriodainfancia.com.br/article.php3?id_article $=232>$. Acesso em: 05 nov. 2013 .
} 
Dessa forma, há uma necessidade urgente que incita a mudanças no ambiente escolar que vão além de modificar a sua organização quanto aos conteúdos e métodos de ensino ${ }^{14}$. Nesse sentido, mostra-se cada vez mais necessário transformar as mentalidades no que concerne à educação formal ${ }^{15} \mathrm{e}$ informal, destacando-se que para o aprendizado dos conteúdos básicos referentes à primeira, faz-se necessário que as crianças e adolescentes se sintam confortáveis e acolhidos no ambiente escolar $^{16}$, tendo em vista que seu desempenho satisfatório está intimamente ligado às relações interpessoais que estabelecem nesse ambiente ${ }^{17}$. Sem o relatado, há fortes probabilidades de o seu desempenho vir a ser prejudicado por diminuição da concentração, desinteresse gradual pelos estudos, dificuldade de aprendizagem podendo gerar autoexclusão, faltas e, até mesmo, evasão escolar ${ }^{18}$.

É importante ressaltar que a escola é o local onde a maioria dos indivíduos estabelece grande parte das suas relações sociais quando ainda se encontram na primeira etapa de seu desenvolvimento físico e mental, tendo em vista que uma criança passa a frequentar uma escola, nos dias atuais, em média, aos quatro anos de idade (o que não quer dizer que muitas já não estejam incluídas nesse ambiente muito antes disso, em função do fato de cada vez mais a mulher estar inserida no mercado de trabalho). Sendo assim, boa parte das relações interpessoais estabelecidas pela criança será realizada nesse ambiente, o qual terá, dessa forma, grande influência na sua formação enquanto pessoa. Dessa forma, faz-se necessário que as escolas analisem de forma cada vez mais aprofundada os aspectos relacionados a essa prática no ambiente escolar, sempre lembrando que a escola deve ser um ambiente que seja seguro, saudável, que proporcione condições aos indivíduos de se desenvolver plenamente.

\section{A INTERFERÊNCIA DO BULLYING NA APRENDIZAGEM E O PAPEL DA ESCO- LA PARA SUA SUPERAÇÃO}

Os casos relatados de bullying têm sido cada vez mais frequentes na sociedade, devendo-se levar em conta ainda que muitos deixam de ser conhecidos

\footnotetext{
14 SILVA, Ana Beatriz Barbosa Silva. op. cit. p. 63.

15 SILVA, Ana Beatriz Barbosa Silva. op. cit. p. 79.

16 LOPES NETO, Aramis A. op. cit., p. 166.

17 BEANE, Allan. Proteja seu filho do bullying: impeça que ele maltrate os colegas ou seja maltratado por eles. Tradução Débora Guimarães Isidoro. 2. ed. Rio de Janeiro: Best Seller, 2011, p. 57-60.

18 FANTE, Cléo; PEDRA, José Augusto. Bullying escolar: perguntas e respostas. Porto Alegre: Artmed, 2008 , p. 40.
} 
devido ao fato das vítimas não informarem, por medo ou outros motivos, acerca dos ataques que vêm sofrendo. Esta prática tem sido analisada até mesmo por muitos estudiosos do tema como um "padrão de agressão"19, o qual pode ser encontrado na escola, entre alunos ou entre estes e os professores mas apresenta-se, também, enquanto padrão nas relações familiares e nas relações de trabalho.

Caracteriza-se pelo fato de haver intencionalidade de comportamento agressivo por parte do bullie em relação ao agredido, pela repetição ao longo do tempo e, ainda, pelo desequilíbrio de poder entre agressor e vítima, estabelecendose como uma forma de afirmação de poder interpessoal do primeiro com relação ao segundo que se dá pela agressão física e/ou psicológica.

$\mathrm{Na}$ literatura e em pesquisas acerca do tema há relatos atestando que esse tipo de violência traz às suas vítimas os mais diferentes tipos de doenças, as quais poderão ser tanto psíquicas quanto físicas, sendo considerado como uma das características marcantes da ocorrência do bullying a queda no rendimento escolar dos indivíduos que o sofrem, bem como o medo de frequentar a escola. É o que se demonstra nos dados abaixo colacionados:

Pesquisa realizada pela Organização Não Governamental Plan Brasil em 2010, com 5.168 alunos de todo o país revelou que quanto mais frequentes os atos repetitivos de maus tratos contra um determinado aluno, mais tempo dura essa violência. A constatação demonstra que a repetição das ações de bullying fortalece os agressores e reduz as possibilidades de defesa das vítimas. Este resultado indica ser essencial uma rápida identificação destas ações e imediata reação para conter este tipo de atitude. Ainda segundo a pesquisa, o bullying é mais comum nas regiões Sudeste e Centro-Oeste, e a incidência maior está entre adolescentes na faixa de 11 a 15 anos de idade, que frequentam a sexta série do ensino fundamental. Os agressores geralmente cometem os maus tratos para obter popularidade entre os colegas, para serem aceitos ou simplesmente se sentirem poderosos. No caso das vítimas, estas costumam apresentar algum traço característico marcante (obesidade, baixa estatura), algum tipo de necessidade especial ou o uso de roupas consideradas diferentes pela maioria dos colegas. "Os jovens tímidos, com dificuldades para se expressar, são alvos em potencial. Os primeiros sinais apresentados geralmente são a queda no rendimento escolar e o medo de frequentar

${ }^{19}$ MALDONADO, Maria Tereza. Bullying e Ciberbullying: o que fazemos com o que fazem conosco? São Paulo: Moderna, 2011, p. 22. 
a escola", explica José Antonio. "O problema é que a maioria das escolas não está preparada para reconhecer essa prática, já que a linha que separa o bullying da brincadeira é muito subjetiva"20.

A Escola deve ser um lugar onde, crianças e adolescentes, sintam-se seguros, devendo representar a estes apenas o local onde frequentam para serem ensinados, haja vista que a educação é um direito consagrado a estes pela Constituição Federal, pelo Estatuto da Criança e do Adolescente (ECA) e pela Convenção sobre os Direitos da Criança da Organização das Nações Unidas ${ }^{21}$; contudo, a violência provocada pelos bullies (agressores) reduz as condições de aprendizado daqueles que são vitimados, como aduz Maldonado ${ }^{22}$ :

Crianças e jovens estão com o cérebro em formação. Com os conhecimentos mais recentes da neurociência, principalmente com o conceito de neuroplasticidade, sabemos hoje que os circuitos neuronais são formados durante toda a vida, e que a influência da escola, da relação dos educadores e da relação das famílias com o cérebro em formação é muito importante. [...] Caminhos neurais podem ser pisados e repisados no padrão de agressão ou de sofrimento. Caminhos neurais podem ser feitos e refeitos quando vamos mudando a maneira de olhar a qualidade dos relacionamentos. [...]. Sabemos hoje que os ataques de angústia, de ansiedade e de medo, e muitas vítimas de bullying sofrem isso de uma maneira muito intensa, vão prejudicando a capacidade de concentração e de aprendizagem.

Bem como Fante ${ }^{23}$ :

[...] as situações constrangedoras e as formas de exclusão sócio-educacionais a que foram submetidos os alunos produziram registros traumáticos em seus arquivos de memória [...]. Tais situações repetidas, repetidas diariamente, acabaram por criar zonas doentias, que funcionam como [...] verdadeiro ancoradouro que aprisiona as emoções humanas, impede [...] habilidades de autodefesa e de socialização, além de prejudicar o seu desenvolvimento educacional na medida em que promove seu isolamento.

\footnotetext{
${ }^{20}$ CASOS de bullying em escolas preocupam pais e educadores. Terra, Notícias. 29 de julho de 2010. Disponível em: < http://noticias.terra.com.br/educacao/noticias/0,,OI4594588-EI8266,00-Casos + de+bullying + em + escolas + preocupam + pais $+\mathrm{e}+$ educadores.html $>$

${ }^{21}$ LOPES NETO, Aramis A. op. cit. p. 165.

${ }^{22}$ MALDONADO, Maria Tereza. op. cit., p. 36-37.

${ }^{23}$ FANTE, op. cit., p. 78-80.
} 
Destaca-se ainda que aqueles que agridem, normalmente, desde cedo apresentam como característica "aversão às normas, não aceitam serem contrariados ou frustrados"24, ou seja, demonstram total desrespeito às regras sociais, buscando estabelecer no ambiente escolar um modelo próprio de conduta; mas a escola, como qualquer lugar onde se convive com diferentes pessoas, tem seus padrões estabelecidos na moral média da sociedade onde está inserida, determinando que aqueles que nela convivem, se moldem a este modelo. Como aduz Piaget, "toda moral consiste num sistema de regras, e a essência de toda moralidade deve ser procurada no respeito que o indivíduo adquire por essas regras" ${ }^{25}$.

Sendo assim, cabe aos educadores identificar as possíveis situações de conflito que poderão surgir quando há o descumprir das regras por bullies, buscando, de forma preventiva, interagir com os educandos a fim de conseguir com que haja um maior respeito no trato entre os estudantes, favorecendo, dessa forma, o processo de construção dos valores sociais e, por consequência, do próprio conhecimento. Deve-se evitar qualquer tipo de omissão dos professores no sentido de interferir na continuidade do processo de bullying, estando estes preparados para agir nas mais diferentes situações, mesmo quando estiver diante da total ausência de diálogo da vítima e/ou agressor com seus educadores.

Cabe ressaltar que certa agressividade e violência até faz parte da vida das crianças e da escola, já que essa característica é inerente a todo ser humano e somente na medida em que os indivíduos vão sendo civilizados, educados, formando sua personalidade, é que se aprende a "domar" a agressividade ${ }^{26}$; contudo, deve-se estar atento para perceber se a criança não está perdendo a empatia pelo outro, sempre ressaltando os valores inerentes à convivência social ${ }^{27}$.

Muito se discute da necessidade de que a Escola reveja seus métodos de ensino, intervindo nos modelos pedagógicos convencionais, de tal forma que a educação se torne cada vez mais crítica quanto às suas bases curriculares, se comprometendo com modelos emancipatórios, que tragam "novas formas de elaboração, implantação, desenvolvimento e avaliação do currículo e formação de educadores, coerentes com a concepção crítico-emancipadora do currículo" ${ }^{28}$. Nesse sentido, a escola também deve perceber aquilo que ocorre com os seus alunos,

${ }_{24}$ SILVA, Ana Beatriz Barbosa Silva. op. cit., p. 43.

25 PIAGET, op. cit,. p. 23.

${ }^{26}$ FANTE, op. cit., p. 44-47.

${ }^{27}$ MALDONADO, op. cit., p. 55-60.

28 SAUL, Ana Maria; SILVA, Antônio Fernando Gouvêa. Políticas Curriculares: novos olhares. Revista Educação (História da Pedagogia 4), p. 54-61, dez. 2010, p. 56. 
reconhecendo os fatores que interferem no aprendizado destes, sendo o bullying fato determinante no que diz respeito à diminuição do rendimento escolar.

Cabe ressaltar que se mostra contraproducente o repensar dos métodos tradicionais de ensino para que estes se tornem mais adequados às necessidades educacionais da atualidade, se isso for realizado de forma descontextualizada, e sem significação crítica para os educandos neles inseridos; por isso mesmo, se faz necessário repensar não somente os modelos pedagógicos de uma nova forma, mas também inserir a escola, em todas as suas vertentes, na discussão acerca do que vem ocorrendo, de forma sistemática, entre os seus alunos, entre alunos e professores, percebendo até que ponto as doenças psíquicas e físicas geradas pelo bullying trazem consequências nos processos de aprendizagem.

\section{O PAPEL DA FAMÍLIA PARA RESOLUÇÃO DESSE CONFLITO}

Como fora outrora apresentado, o Bullying causa muitos transtornos de caráter psicofísico às suas vítimas, sendo de fundamental importância que a família se mostre disposta a acompanhar quem sofre essa violência.

Em primeiro lugar, a criança ou adolescente deve ter liberdade para conversar com a família de forma direta sobre o que está acontecendo, incentivando-o a "manter abertas as linhas de comunicação", mas sem rotulá-lo como vítima ${ }^{29}$. Busque descobrir o que aconteceu, evitando reações intensas ao que for dito por seu filho, fazendo perguntas (mas sem fazer um interrogatório) acerca do assunto, registrando tudo por escrito, quando possível ${ }^{30}$. Eleve a autoestima dele, destacando suas qualidades e capacidades, evitando qualquer tipo de insinuação que o faça se sentir culpado pelo que está ocorrendo, ou ainda, que o incentive a revidar, posto que esta atitude, dizem os especialistas, somente geraria mais violência ${ }^{31}$.

Contudo, há crianças e adolescentes que não irão relatar que estão sendo vítimas de bullying. Nesse caso, a família deve estar atenta a alguns sinais, acerca do filho:

Apresenta, com frequência dores de cabeça, pouco apetite, dor de estômago, tonturas, sobretudo de manhã̃? Muda de humor de maneira inesperada, apresentando explosões de irritação?

\footnotetext{
29 BEANE, Allan. op. cit., p. 95.

30 Ibidem, 2011, p. 96-98.

31 FANTE, op. cit., p. 75-76.
} 
Regressa da escola com roupas rasgadas ou sujas e com o material escolar danificado? Apresenta desleixo gradual nas tarefas escolares? Apresenta aspecto contrariado, triste, deprimido, aflito ou infeliz? Apresenta contusões, feridas, cortes, arranhões ou estragos na roupa? Apresenta desculpa para faltar às aulas? Raramente possui amigos, ou possui ao menos um amigo para compartilhar seu tempo livre? Pede dinheiro extra à família ou furta? Apresenta gastos altos na cantina da escola? ${ }^{32}$

Ademais, também se recomenda discutir o que pode ter provocado o bullying, tendo em vista que existem casos onde criança ou adolescente vitimizado pode "ter inadvertidamente contribuído para ser maltratado"33, como quando ele é "autoritário, irritante, temperamental, está sempre interrompendo os outros ou é agressivo [...], tem características comportamentais que dificultam sua aceitação", como o TDAH e o transtorno opositor-desafiador ${ }^{34}$.

Mas ressalta-se, que mesmo nestes casos, "ninguém merece ser maltratado, mas, às vezes, a vítima precisa fazer algumas mudanças" 35 , sendo muito importante que a família acompanhe o que vem acontecendo e coopere para que aquelas venham a ocorrer.

Nesse sentido, muitas crianças e adolescentes que têm, por exemplo, os transtornos acima citados, quando encaminhadas para o tratamento adequado, começam a se comportar de forma diferenciada e ocasionam um comportamento distinto com relação a elas também, cessando o bullying.

Os pais devem ainda verificar se a escola tem regras contra o bullying e ver como melhor reportar o incidente, cobrando da escola que aja de acordo com a política adotada. Caso a escola não tenha essas normas, os pais devem incentivar a sua adoção e se esta não for suficiente, devem buscar o seu aprimoramento.

A escola sempre deverá estar ciente do que está ocorrendo, devendo também o professor do aluno vítima ser notificado, o que, contudo, não deverá ser feito no turno de aulas do filho, posto que isto poderá constrangê-lo ainda mais frente aos colegas e piorar a agressão.

Seja específico quanto às agressões sofridas (por isso a importância da anotação já relatada) e também busque que a escola esclareça o que vai fazer a respeito. Há escolas e professores que serão mais cooperativos, mas há aqueles que

\footnotetext{
32 FANTE, op. cit., p. 77.

33 BEANE, op. cit., p. 112.

34 Idem.

35 Idem.
} 
negarão a existência do bullying e ainda poderão colocar a culpa no agredido pelas agressões, dizendo que a criança ou o adolescente "não é muito querido por aqui" ${ }^{6}$.

Caso a escola se negue a agir, ou o faça insuficientemente, os pais poderão procurar um advogado para que este entre com uma medida cautelar para que sejam cessadas as agressões e devidamente responsabilizados os bullies (e seus responsáveis).

Caso o bullying implique em ataques físicos, tire fotos de todos os ferimentos com uma régua ao lado deles para comprovar seus tamanhos, faça um registro de todas as despesas médicas e psicológicas, sempre datando cada uma das fotos e registros para que fiquem bem claras as ações, fazendo boletim de ocorrência das mesmas se necessário. Contudo, faz-se necessário estar ciente que ao comunicar a polícia do ocorrido, poderá ter pontos negativos, "atraindo atenção indesejada para seu filho, ou, inversamente, conduzindo-o ao isolamento" ${ }^{\text {"37 }}$.

Mas isso não deve ser impedimento para comunicação quando os pais acharem que esta é necessária, tendo em vista que a mesma, quando comunicada à Escola, pode fazer com que cesse a violência.

Ademais, e talvez o mais importante, é que a família deve acompanhar sempre o filho, saber tudo o que ocorre com este e participar efetivamente de sua vida na Escola e fora dela. Faz-se importante tal assertiva, tendo em vista que atualmente, a maior queixa que se encontra nos meios escolares é a de que os pais têm delegado, ou como se diz no meio escolar, "terceirizado" ${ }^{38}$ para a Escola a educação dos filhos, não tomando conhecimento de nada que ocorre com os mesmos.

Para que haja uma diminuição do bullying no ambiente escolar, faz-se necessário que Escola e pais trabalhem em conjunto, de tal forma que conscientizem as crianças e os adolescentes de que tal prática causa danos a todos os envolvidos, independentemente de que lado a pessoa esteja tendo em vista que o bullying demonstra uma total falta de respeito e tolerância para com o próximo, situação esta que dentro e fora do ambiente escolar gera situações de exclusão e injustiças.

\section{CONSIDERAÇÕES FINAIS}

Como se pode analisar, o Bullying se refere a um conjunto de práticas violentas de caráter intencional e repetitivo, realizado por um ou mais agressores,

\footnotetext{
36 BEANE, op. cit., p. 115.

37 Ibidem, 2011, p. 117.

38 MALDONADO, op. cit., p. 139.
} 
contra suas vítimas que se dá, principalmente, no meio escolar, a qual é realizada por meninos e meninas, com o fim de agredir intencionalmente uma pessoa ou um grupo de pessoas, considerados pelos bullies como pessoas fracas e que não se adéquam ao meio onde estão inseridas.

Suas vítimas, em razão da violência ocasionada pelo bullying, poderão vir a desenvolver diferentes doenças psíquicas e/ou físicas, as quais tendem a comprometer o seu desempenho escolar por diminuição da concentração, desinteresse gradual pelos estudos, dificuldade de aprendizagem, o que pode gerar exclusão, faltas e evasão escolar, pelo fato de que a vítima tem a escola como um local de segregação, de sofrimento.

Cabe à Escola e à família se atentarem para esta prática, estando alerta aos "sinais" que a prática do Bullying gera no ambiente escolar e em suas vítimas. Crianças e adolescentes devem ter em seus professores e em seus pais pessoas comprometidas e abertas ao diálogo, podendo, dessa forma, encontrar nestes o apoio e o refúgio necessário à superação dessa violência.

O Bullying deve ser amplamente discutido com os alunos, por meio de campanhas realizadas nas escolas, e também nos meios de comunicação em geral, a fim de que se obtenha cada vez mais a consciência de que esta prática é errada e ocasiona um mal a todos os envolvidos.

Mas é de suma importância a participação efetiva dos pais, informando e apoiando seus filhos, e se comprometendo em apoiá-los quando vítimas de tal prática, ou de repreendê-los quando agressores. Esta atitude é tão ou mais importante que a primeira, tendo em vista que um bullie que não sofre penalidades por sua prática poderá perpetuá-la por toda sua vida, se tornando um indivíduo intolerante e que não respeita as regras sociais.

A diminuição do Bullying nas escolas (e, por assim dizer, até fora delas) implica em uma necessária parceria Escola/família, bases formadoras de valores que formam uma sociedade mais justa e solidária, baseada no respeito, tolerância e na inclusão social.

\section{REFERÊNCIAS}

ABRAPIA. Associação Brasileira Multiprofissional de Proteção à Criança. Pesquisa realizada pela ABRAPIA em 2002/2003 no município do Rio de Janeiro. Disponível em: <http://www.observatoriodainfancia.com.br/article.php3?id_ article $=232>$. Acesso em: 05 nov. 2013. 
BEANE, Allan. Proteja seu filho do bullying: impeça que ele maltrate os colegas ou seja maltratado por eles. Tradução Débora Guimarães Isidoro. 2. ed. Rio de Janeiro: BestSeller, 2011.

CASOS de bullying em escolas preocupam pais e educadores. Site Terra, Notícias. 29 de julho de 2010. Disponível em: <http://noticias.terra.com.br/educacao/ noticias/0,,OI4594588-EI8266,00-Casos + de + bullying + em + escolas + preocupam + pais + e+educadores.html >. Acesso em: 10 set. 2011.

FANTE, Cléo. Fenômeno Bullying: como prevenir a violência nas escolas e educar para a paz. 6. ed. Campinas: Verus, 2011.

FANTE, Cléo; PEDRA, José Augusto. Bullying escolar: perguntas e respostas. Porto Alegre: Artmed, 2008.

COMPORTAMENTO: bullying. Revista Psicanálise, n. 1, p. 38-45, 2010.

JORDÃO, Cláudia. Entrevista Allan Beane: as escolas fecham os olhos ao bullying. Revista Isto É. 21 abril 2010. p. 9-11, 2010.

MALDONADO, Maria Tereza. Bullying e Ciberbullying: o que fazemos com o que fazem conosco?. São Paulo: Moderna, 2011.

LOPES NETO, Aramis A. Bullying: comportamento agressivo entre estudantes. Jornal de Pediatria, v. 81, n. 5 (Supl), S164-172. 2005. Disponível em: <www.scielo.br/ pdf/jped/v81n5s0/v81n5Sa06.pdf> . Acesso em: 10 set. 2011.

LIMA, Raimundo de. Massacre nas Escolas. Revista Espaço Acadêmico, n. 96, maio 2009. Disponível em: <http://www.espacoacademico.com.br/096/96lima.htm>. Acesso em: 05 nov. 2011.

PIAGET, Jean. O juízo moral na criança. 2. ed. São Paulo: Summus, 1994.

SAUL, Ana Maria; SILVA, Antonio Fernando Gouvêa. Políticas Curriculares: novos olhares. Revista Educação (História da Pedagogia 4), p. 54-61, dez. 2010.

SILVA, Ana Beatriz Barbosa. Bullying: mentes perigosas nas escolas. Rio de Janeiro: Objetiva, 2010. 
SILVA, Elenice da. Corredores de justiça: combatendo a prática do Bullying nas escolas, educando uma sociedade para a paz. São Paulo: Ed. do Autor, 2009.

Recebido em: 07 de julbo de 2015 Aceito em: 16 de dezembro de 2015 